\title{
Promoting Charity Accountability: Understanding Disclosure of Serious Incidents
}

\section{Diarmuid McDonnell, University of Birmingham \\ Alasdair C Rutherford, University of Stirling}

\begin{abstract}
Charities are under increasing pressure to be accountable. Using a novel dataset, we provide the first analysis of the characteristics of charities voluntarily disclosing details of serious incidents that may threaten their organisation. Financial loss, fraud and theft, and personal behaviour account for a majority of serious incidents reported. Larger, older organisations that have previously been subject to a regulatory investigation are more likely to report serious incidents. However, it is smaller, younger charities where the regulator perceives there to be greater risk of organisational demise arising from the incident.
\end{abstract}

Keywords: performance accountability; charity transparency; charity regulation; charity risk; nonprofit accountability 


\section{Introduction}

Faith in the charity sector has been questioned as a result of a number of high-profile scandals (e.g. financial mismanagement at Kids Company, intrusive requests for fundraising in the Olive Cook case), prompting calls for greater transparency. As Brody (2002, p. 472) attests, the charity sector's claims "to exist for the public good are no longer being taken on faith, and more people believe they have a stake in the accountability of nonprofits." Researchers ascribe the increasing interest in accountability to two prominent factors: the size and significance of the sector in many countries, and low barriers to entry (Connolly, Hyndman \& McConville, 2013; Prakash \& Gugerty, 2010). These developments have, they argue, resulted in greater potential for less trustworthy organisations to join the sector. It is therefore imperative to understand the degree of serious incidents triggered or experienced by charities, and their willingness to be transparent about such incidents. The aim of this paper is two-fold. First, we explore the nature and extent of transparency practices about serious incidents.

Second, we examine which factors account for variation in the reporting of these incidents by charities.

The salience of our research is derived from three wider developments. First, charities in the UK are subject to intense public, political and media scrutiny (Office of the Scottish Charity Regulator, 2016a). Operating in this climate presents a risk to charities in the form of declining levels of public trust and confidence, both of which are acknowledged as being crucial to the long-term success of the sector in generating support (Connolly \& Hyndman, 2013a; Cordery \& Morgan, 2013; Keating \& Frumkin, 2003; Morgan, 2012). Concurrently, the sector suffers from a contamination problem, whereby the reputations of legitimate, ethical charities are tarnished by the misbehaviour - perceived or otherwise - of other organisations (Burger \& Owens, 2010; Ortmann \& Schlesinger 1997). Tremblay-Boire, Prakash and Gugerty (2016) attribute the generation of these negative reputational 
externalities to the information asymmetries in activities and outcomes that exist between charities and their stakeholders. In response to this gap, the same authors argue that credible charities have an incentive to differentiate themselves from less credible ones for the purpose of enhancing their reputations. Second, UK charity regulatory regimes are currently in a state of flux. The Scottish Charity Regulator (OSCR) and the Charity Commission for England and Wales (CCEW) are transitioning to a regulatory approach that is informed by risk assessment and analysis i.e. targeting their resources on areas of work that have the greatest potential to support confidence in the charity sector. In pursuit of this aim, on 1 April 2016 OSCR introduced a number of changes in charity reporting and accountability: these included an amended annual return form capturing more governance information, an accountability mechanism for charities to report serious incidents (the subject of this study), and publishing online the annual reports and accounts of particular types of charities. Third, the increased availability of large-scale administrative data about the charity sector, facilitated by projects such as the Scottish Network for Third Sector Data and the Scottish Civil Society Data Partnership, enables researchers to examine aspects of behaviour and accountability in novel, comprehensive ways (Brook \& Rutherford, 2017; McDonnell, 2017; McDonnell \& Rutherford, 2017).

Using a novel dataset, we provide the first analysis of the characteristics of charities voluntarily disclosing details of serious incidents that may threaten their organisation. Our findings show that financial loss, fraud and theft, and personal behaviour account for a majority of serious incidents reported; and larger, older organisations that have previously been subject to a regulatory investigation are more likely to report said incidents. Our research makes three main empirical contributions to the literature. First, it provides a comprehensive account of the factors associated with the willingness of charities to discharge accountability for serious incidents; in particular, our findings reinforce the salience of 
organisational capacity in predicting accountability behaviour (Saxton \& Guo, 2011; Saxton, Kuo \& Ho, 2012; Tremblay-Boire \& Prakash, 2015). In doing so the research builds on the growing body of scholarship on non-financial forms of transparency and disclosure (Gray, Brennan \& Malpas, 2014; Lehman \& Kuruppu, 2017; Lehman \& Morton, 2017). Second, we provide one of the fullest accounts of the serious incidents experienced by charities, and in doing so make a novel contribution to the evidence base on charity misconduct and sustainability - a matter of considerable relevance to bodies responsible for monitoring the sector (Saxton et al., 2012). Such studies are particularly important for understanding a sector in which losses from fraud alone are estimated as £1.9 billion per year (PKF Littlejohn, 2016). Finally, this research responds to the call to understand the sectoral, organisational and instrumental contexts in which charity accountability occurs (Prakash \& Gugerty, 2015; Tacon, Walters \& Cornforth, 2017). This work has considerable implications for regulators concerned with targeting their resources on the significant issues and incidents prevalent in the charity sector.

\section{The Scottish Charity Sector}

Scotland has a heterogeneous charity sector comprising of over 24,000 organisations working across numerous geographies, beneficiary groups and charitable purposes. The sector makes a significant contribution to Scotland's economy and society: in 2013 charities were estimated to employ 138,000 people, have total revenues of almost $£ 5$ billion and to have spent $£ 4.7$ billion on programme expenditure (Scottish Council for Voluntary Organisations, 2014). OSCR was established in 2005 and acts as the independent regulator and registrar of charities in Scotland. Though not a statutory duty, one of OSCR's main aims is to protect public confidence in the sector and it implements a number of programmes that it believes will help achieve this, one of which is the serious incident reporting scheme.

\subsection{Serious Incident Reporting}


From 01 April 2016, OSCR requests that charities report certain types of serious incidents through its Notifiable Events reporting scheme; these are incidents, ongoing and historical, that threaten to have a significant impact on the charity or its assets. Incidents are not expected to be uniform, in nature or distribution, across the sector and their seriousness will most probably be a function of charity size and type (Office of the Scottish Charity Regulator, 2016b). The Notifiable Events reporting scheme complements OSCR's wider monitoring and compliance work (in particular its investigation of alleged wrongdoing), and is borne from a desire to:

support public confidence in charities and their work. Part of our role is to try and prevent problems from happening, by providing guidance and advice to charities. Where problems have occurred, we want to help minimise the impact to the individual charity and the charity sector overall. (Office of the Scottish Charity Regulator, 2016b, p. 1)

The aims of the reporting scheme are to get charities thinking about risk, and to encourage them to interact with the regulator outside of the regular annual reporting periods. Charities are not under a legal obligation to report serious incidents; however, OSCR recommends such transparency as an effective mechanism for trustees to discharge accountability as part of their governance duties. The incidents that OSCR deems serious and notifiable are not strictly defined, but OSCR provides a list of examples including: fraud and theft; substantial financial loss; incidents of abuse or mistreatment of vulnerable beneficiaries; too few charity trustees to make a legal decision; charity has been subject to a criminal investigation or an investigation by another regulator or agency; sanctions have been imposed, or concerns raised by another regulator or agency; significant sums of money or other property have been donated to the charity from an unknown or unverified source; suspicions that the charity and/or its assets are being used to fund criminal activity (including terrorism); and a charity 
trustee is acting whilst disqualified (Office of the Scottish Charity Regulator, 2016b). Upon receipt of a report, OSCR considers three responses: whether the incident requires further reporting by the charity; whether the charity should be referred to its regional support body Third Sector Interface (TSI); and whether the incident carries a risk of organisational demise. ${ }^{1}$ Certain charities are not expected to report serious incidents: Registered Social Landlords and Cross Border charities, as they are subject to regulation by the Scottish Housing Regulator or the Charity Commission for England and Wales respectively.

\section{Charity Accountability}

Bovens (2007, p. 452; see also Ebrahim, 2005) defines accountability as "a relationship between an actor and a forum in which the actor is obliged to explain and justify his conduct; the forum can pose questions; pass judgment; and the actor may face consequences." There are various normative reasons why accountability occurs: it addresses information asymmetry between a principal and an agent; it can contain agency losses; it can ensure that agents adhere to their mandate; and the agent feels it has a moral duty to discharge accountability (Busuioc \& Lodge, 2016). It is a multidimensional concept and the literature as it relates to charities identifies two that are of particular importance: fiduciary accountability and performance accountability (Brody, 2002; Connolly \& Hyndman, 2004; Goodin, 2003). Performance accountability has two sub-dimensions which are worth delineating in the context of this study: process accountability (e.g. the administration of the charity, its decision-making framework) and substantive accountability (e.g. the outputs, outcomes, and

\footnotetext{
${ }^{1}$ These are captured in the data and only represent OSCR's responses to date. It is conceivable that a greater range of responses will occur as different incidents are reported over time; for example, a reported incident might lead to a regulatory investigation and subsequent intervention.
} 
impact of a charity with respect to its mission-driven goals and objectives) (Frumkin, 2006; Saxton \& Guo, 2011).

Much of the empirical work in this field focuses on a specific aspect of charity accountability: transparency. This refers to the provision of information by a charity to one or more stakeholders, often without the expectation of facilitating dialogue and discussion about said information. Early contributions by Hyndman $(1990,1991)$ established a methodology and conceptual framework for research on charity transparency. The author examined the annual reports and reviews of the top 100 fundraising charities in the $\mathrm{UK}$ and produced a checklist of 14 information types that charities either did or should provide to donors. This work was revisited by Connolly and Hyndman (2013) in their mixed-methods study of information disclosure by the top 100 fundraising charities in the UK; they found that respondents felt donors and beneficiaries respectively are the stakeholders to which charities are most accountable. The scholarly focus on charity accountability bifurcated in the early 2000s. One strand examined the discharge of financial information through compliance with the Statement of Recommended Practice (Connolly \& Hyndman, 2000, 2001). These studies found that financial disclosure practices had improved over time but varied across different types of charities and jurisdictions. The other strand analysed the nature and extent of financial and non-financial (narrative) information discharged by charities through their annual reports and reviews (Connolly \& Dhanani, 2006; Connolly \& Hyndman, 2004; Dhanani, 2009; Hyndman \& McConville, 2015; Morgan \& Fletcher, 2013; Yasmin, Haniffa \& Hudaib, 2014). These studies consistently revealed that performance reporting improved over time, larger charities are more likely to discharge this type of information, and there is a lack of engagement in substantive accountability.

Recent studies have shifted emphasis to uncovering the factors associated with a charity's willingness to disclose voluntarily information through online media. Saxton and Guo (2011) 
posited that variation in the web-based accountability practices of charities was explained by a theoretical model comprising four factors (eight variables): strategy (geographical scope of operations and unrestricted reserves), capacity (organisation size and age), governance (financial stewardship and board performance), and environment (regional poverty and organisational density). Using a sample of 117 community foundation in the US, Saxton and Guo (2011) document that governance and capacity factors were most the significant in accounting for variation in accountability behaviour. Saxton, Kuo and Ho (2012) extended this model by employing alternative measures for some of the four factors and applying the framework to the population of not-for-profit hospitals in Taiwan $(N=40)$. The authors found that "the larger the institution, the greater the financial leverage, the smaller the size of the board, and the higher the percentage of outside board members, the less likely it is that an institution will voluntarily disclose its financial information.” (Saxton et al, 2012, p. 1066). Tremblay-Boire and Prakash (2015) also examined the determinants of online accountability by U.S. nonprofits but derived alternative explanatory factors from the organisational legitimacy and stakeholder theory literatures. They posited that media exposure, industry, organisation size, and government funding are predictors of online information disclosure. Their results suggest that organisations subject to greater media exposure and who operate in the education, health or religious sectors are more likely to engage in online accountability, while larger nonprofits are less likely. In their study of Chinese foundations, Nie, Liu and Cheng (2016) employ variables derived from resource dependence and institutional theory perspectives to examine variation in voluntary information disclosure. The authors found that - after controlling for organisation size, age, type and managerial capacity - "foundations with greater dependence on donations and restricted funds are more likely to disclose information to the public voluntarily as a means of satisfying resource providers." (Nie et al., 2016, p. 2397). 
This paper addresses one of the key themes identified in the charity accountability and governance literature by Prakash and Gugerty (2010, p. 18): “in what domains and regulatory contexts, and in what types of nonprofit, are accountability problems most accentuated?" Tacon, Walters and Cornforth $(2017$, p. 4) also stress the importance of examining "the mechanisms through which nonprofit organizations enact (or might seek to enact) accountability." Despite the proliferation of credible work in this area, our understanding of the factors that predict transparency by charities regarding their conduct and performance is limited. Extant research is characterised by a focus on a dominant stakeholder to whom charities are accountable (donors); small, unrepresentative samples drawn from subsections of the charity sector (e.g. community foundations, charities that derive the majority of their income from donations); the examination of a narrow range of accountability mechanisms (e.g. charity websites and reports); and homogeneity of research method (e.g. content analysis). In this context, we seek to advance the field by focusing on a novel accountability mechanism; one that is voluntary, upward and instrumental in its form (Christensen \& Ebrahim, 2006; Knutsen \& Brower, 2007). The focus on upward accountability to a regulator is particularly important as it is often overlooked in favour of examining downward accountability to donors, beneficiaries and the public (e.g. Morgan \& Fletcher, 2013; Saxton, et al., 2012). Finally, our research makes a significant contribution to the evidence base on charities in the UK, particularly with respect to understanding the risks and concerns prevalent in the sector.

\section{Method}

To study the reporting of serious incidents, we utilise a linked administrative dataset of Scottish charities that is constructed from three sources: the Scottish Charity Register 
containing the complete population of charities (historical and current); annual returns containing financial information submitted by charities to OSCR; and OSCR data on the first year of the Notifiable Events scheme. This dataset provides a pooled cross-section of the charity sector containing 20,400 observations over the period April 2016 - March 2017 inclusive. Table 1 summarises the steps in the sample selection process.

[Table 1 here]

\subsection{Empirical Model}

We adapt the four-factor model developed by Saxton and Guo (2011) to serve as the conceptual framework for our study. We test the effect of seven explanatory variables that correspond to the following four factors: strategy, capacity, governance and environment. These four factors are routinely employed in nonprofit studies due to their salience for understanding organisational behaviour in general (see Behn, DeVries, \& Lin, 2007; Luoma \& Goodstein, 1999; Brody, 2002), and the ability of researchers to operationalise a wide variety of measures corresponding to these factors in a multitude of study settings. Table 2 outlines how these variables map to our conceptual framework. We measure the reporting a serious incident to the regulator using a dichotomous variable that has the value 1 if a charity reports and 0 if it does not. We model the probability of reporting a serious incident as a function of organisation size, (log) age, institutional form, charitable activity, external oversight, regulatory investigation history and geographical scale of operations. As our dependent variable has two mutually exclusive and exhaustive outcomes, we specify a logistic regression model. 
Drawing on the reviewed literature, we operationalise seven independent variables corresponding to four organisational factors. Size is a categorical measure of a charity's most recent annual gross income; we adopt this three-category measure as it is employed by the Regulator for their own analysis of charity accountability and misconduct (alternative functional forms are tested and described in the Results section). In line with previous studies we posit a positive relationship between organisation size and willingness to discharge accountability. Age is the natural logarithm of the number of years an organisation has existed. Parent is a binary indicator of whether a charity has a parent organisation (e.g. parish churches that are part of the national-level Church of Scotland); we include this variable as it is reasonable to assume that having a parent charity affords governance benefits (e.g. access to model constitutions). While information on the make-up of trustee boards would have been desirable to capture other governance characteristics, this information is not currently available in the Scottish Charity Register. Investigated is a binary indicator of whether a charity has been the subject of a regulatory inquiry in the past two years; this measure was chosen as it is plausible that investigated charities experience a greater risk of serious incidents. Local is a binary indicator of whether a charity's geographical scope of operations is limited to a local level i.e. no larger than the area of a local authority; it is important to consider scale of operations, as the nature and locus of serious incidents may vary by scale. Funder is a binary indicator of whether a charity only disburses grants to other organisations rather than carrying out charitable activities itself or a combination of activities; we hypothesise that grant-making organisations differ in their accountability behaviour compared to other charities. Unincorp is a binary indicator of whether a charity is registered as an unincorporated association, as opposed to other constitutional forms such as companies and trusts. Unincorporated charities face different legal constraints on the types of activities 
they can engage in (e.g. they cannot sue or be sued), and so may themselves differently in comparison to their counterparts.

[Table 2 here]

\section{Results}

The sample contains demographic, financial and investigations data on 20,400 active charities. The vast majority of organisations are defined as Standard charities (95 percent); the remainder are Cross-Border charities or Registered Social Landlords. The mean and median charity has $£ 1,214,998$ and $£ 21,127$ in annual gross income respectively; the mean and median age in the sample is 25 years and 16 years. The three most common constitutional forms for Scottish charities are unincorporated associations (50 percent), companies (22 percent) and trusts (16 percent). Fifteen percent of charities have a parent organisation, while 32 percent disburse grants to individuals and organisations. Finally, there is a large degree of geographical variation in the sector, with 43 percent of charities operating only at a local level, seven percent across Scotland and other parts of the UK, and thirteen percent operating overseas.

\subsection{Describing Serious Incidents}

OSCR has received reports from 94 charities concerning 115 serious incidents (less than one percent of charities in the sample). Almost 50 percent of these reports concerned financial loss or fraud and theft, followed by 10 percent referring to the personal behaviour of a trustee or member of staff (e.g. allegations of bullying). Seven percent of charities were unsure of whether they needed to report an issue (listed as 'General Enquiry Clarification').

Figure 1 shows how the frequency of the different types of serious incidents reported map to OSCR's three responses; we feel the regulator's response provides important context as to the 
seriousness and impact of the incident. For 20 charities OSCR deems that the reported incident could potentially lead to the demise of the organisation (i.e. a wind up); twelve of these concerned financial loss. OSCR referred 24 charities to their regional TSI for further support in dealing with the incident. Reports concerning fraud \& theft and personal behaviour most commonly result in the regulator requiring further reporting, but these incidents have not been considered by the regulator to threaten the continued operation of the charity.

\section{[Figure 1 here]}

Figure 2 shows the distribution of serious incidents by charity age and size. Fraud $\&$ theft and financial loss are fairly widely distributed across different types of charity, while personal behaviour is concentrated amongst the largest, oldest organisations. Charities of belowaverage size (using the mean) and average age are most susceptible in the regulator's perspective to incidents that might lead to organisational demise. Few charities aged less than three years, or with income below about $£ 60,000$, report to OSCR through the Notifiable Events scheme (Figure 3)

[Figure 2 here]

[Figure 3 here]

\subsection{Modelling the Reporting of Serious Incidents}

Before discussing the results of the regression analysis in Table 4, Table A3 contains descriptive statistics for the independent variables included in the model. The typical reporting charity appears to be older, larger, more likely to have been subject to a regulatory inquiry, and less likely to limit its operations to a local level. The presence of multicollinearity among the independent variables in the model was examined by calculating the variance inflation factors (VIF): mean VIF is 1.16 and no variable has a VIF greater than 
1.2, below the threshold at which Allison (1999) suggests multicollinearity is problematic. We report log odds, robust standard errors, confidence intervals and a range of model fit statistics as per the guidance of Connolly, Gayle and Lambert (2016).

[Table 3 here]

[Table 4 here]

We first examine the two Capacity factors, beginning with size. The regression coefficient for both categories is positive, which suggests that medium and large charities have higher odds of reporting serious incidents compared to their smaller peers. ${ }^{2}$ The coefficient of age is also positive: a one-unit increase in the log age of a charity results in an increase in the odds of reporting. Taken together, these results point to the salience of organisational capacity in accounting for variation in reporting behaviour; however, it is not yet clear whether charities have greater resources to support their efforts to report, or that larger, older charities experience more of these events (and subsequently report them). We next examine our Environment variables. It appears charities that have been investigated by OSCR in the previous two years have greater odds of reporting. This may indicate external pressure to report (though not every charity is aware that it is/was under investigation); or it may be evidence that certain types of charities are more susceptible to experiencing incidents worth reporting, by the public or the organisation itself, to the regulator. Charities that restrict their operations to a local geography are less likely to report, which may provide tentative evidence of lower levels of serious incidents occurring at smaller scales of operations;

\footnotetext{
${ }^{2}$ We tested the robustness of this finding by employing a different functional form of Size in the model: the natural logarithm of annual gross income. The coefficient is consistent with the original categorical measure: a one-unit increase in the log of income is associated with a statistically significant increase in the odds of reporting $(\beta=.41, \mathrm{p}<.001)$.
} 
however, it could also be argued that these organisations may not have an awareness of the Notifiable Events scheme, or the capacity to report.

Next we examine the effect of our two Strategy factors. The coefficient for grant is negative, suggesting that charities engaged solely in grant-making activities are less likely to report compared to organisations that carry out charitable activities themselves. This is an unsurprising finding when placed in the context of the type of serious incidents OSCR wants to be notified about (e.g. harm or abuse concerning beneficiaries is plausibly less likely to directly occur in the discharging of grants). We see the opposite effect for charities that adopt an unincorporated association legal structure: these organisations have higher odds of reporting compared to other legal forms. Finally, we examine our solitary Governance factor. Having a parent charity is associated with a decrease in the odds of reporting, though it is arguable that this is a proxy measure for governance at best and we are not able to extract from the data an understanding of the relationship between the parent organisation and its charity.

\subsection{Distribution of Risk in the Charity Sector}

The data analysed in the previous section tell us much about the propensity of charities to discharge accountability for serious incidents. However, it constitutes only a partial representation of the wider suite of risks occurring in the sector. Figure 4 explores the distribution of serious incidents reported to OSCR by other stakeholders (e.g. members of the public), specifically incidents that merited action by the regulator (e.g. reporting the charity to prosecutors or suspending trustees); these data are derived from our previous work on charity misconduct and cover the period 2006-2014 (McDonnell \& Rutherford, 2017). For charities of average size and age, the distributions of the incidents captured in the two datasets overlap considerably. However, there are notable differences: larger, older charities are more likely to 
be captured in the Notifiable Events data, while incidents reported by other stakeholders are more likely to cover a wider range of charities that includes smaller, younger organisations. The absence of close alignment is unsurprising, as we should not expect charities to report the same incidents as those highlighted by other stakeholders for two reasons: charities often do not know that a complaint about them has been made to the regulator; and charities are privy to incidents that other stakeholders are not (e.g. quorum or personal behaviour issues).

\section{[Figure 4 here]}

\section{Discussion}

This study investigated the nature, extent and factors associated with the reporting of serious incidents by charities. Concerns relating to financial loss, fraud and theft, and personal behaviour account for a majority of reported incidents, and there is a strong association between the type of incident and the regulator's response. The multivariate regression results show that larger, older organisations that have previously been subject to a regulatory investigation are more likely to voluntarily disclose serious incidents to the regulator. However, it is smaller, younger charities where the regulator perceives there to be greater risk of organisational demise arising from the incidents reported, as evidenced by the distribution of regulatory response in Figure 2. Finally, the Notifiable Events data capture a significant yet partial cross-section of the risks prevalent in the Scottish charity sector.

Our analysis reveals much about the intersection of risk, accountability and regulation in the charity sector. The implications of these findings are framed in Table 5, which maps charities and their presence in the data across two dimensions: motivation to report and experience of a serious incident. Charities who Report events in the first year are both motivated to report, and experienced a serious incident. That is, they were both at risk of a serious incident, and have the necessary governance in place to be accountable. These charities are perhaps best 
considered "early adopters", as they demonstrate a motivation to embrace a novel means of discharging accountability. Consequently, "early adopter" organisations may be using the reporting scheme to signal their credibility and concern with good governance to the regulator (Phillips, 2013; Tremblay-Boire et al., 2016). These are distinguished from charities who may report In Future; they have appropriate governance in place, but have not yet experienced a serious incident. In contrast, charities who are unmotivated to report or are unaware of the scheme will not appear in the data. If they do not experience a serious incident then this is unproblematic (Never); however there is likely to exist a group of charities that have experienced serious incidents which remain Unreported.

\section{[Table 4 here]}

Evidence from a similar scheme implemented by the Charity Commission for England and Wales may reveal how many incidents we can expect to be reported in a given year. 2,181 serious incidents were reported in 2016-17 (Charity Commission for England and Wales, 2017); given that the Scottish charity sector is approximately fifteen percent the size of its nearest neighbour, OSCR may expect around 300 reports per annum, rather than the 115 recorded in the first year. Therefore it is likely that currently many events are going unreported, and more needs to be done to raise awareness amongst charities in order to move them from the Unreported to Reported groups. It will be interesting to see whether the rate of reporting increases in response to external pressures or threats to organisational legitimacy (e.g. from a sector-wide scandal); previous studies suggest that organisations increase their transparency activities in response to scrutiny, though this act may be symbolic and not lead to substantive changes in behaviour (Coetzee \& van Staden, 2011; Islam, Dissanayakeb, Dellaportas \& Haque, 2018; Parsa, Roper, Muller-Carmen \& Szigetvari, 2018). Longitudinal 
data from future waves, combined with other risk-related regulatory data, will allow us to better distinguish the four groups, and understand this intersection of risk and accountability.

Our findings are also relevant to charities and those who advise them (e.g. auditors, accountants, infrastructure bodies and regulators). Charities can be reassured by the wide distribution of serious incidents occurring across the sector, and that they are not singled-out by reporting a serious incident. For professional advisors, our comparison with the reporting rate in England \& Wales suggests charities need to engage more in demonstrating accountability for experiencing and managing risks. Under-reporting may be due to ignorance of the Notifiable Events scheme amongst some charities, or uncertainty about what constitutes a serious incident. Ten of the incidents in the data were nothing more than requests for clarification on reporting, none of which led to further regulatory response. This suggests that charities need a clearer understanding of the scheme, and both the regulator and charities' advisors have an important role in supporting organisations to engage with the regulator in this way.

From a regulatory perspective, identifying patterns in the distribution of serious incidents can assist OSCR in targeting its resources at those charities and issues that present threats to the regulator's ability to achieve its objectives. One of the most pressing considerations for OSCR is whether and how to communicate the insights generated by this study's findings to a wider audience. It could be argued that OSCR has a moral duty to disclose information on serious incidents, particularly in the context of the significant reputational and operational benefits the public bestows on charities (Morgan, 2012). However, would such a proactive release of information without context - what Coglianese (2009) terms "fishbowl transparency" - reduce the information asymmetries that exist between charities and their external stakeholders (Tremblay-Boire \& Prakash, 2017)? There are long-standing concerns about the ability of stakeholders to parse financial and performance information that must be 
taken into consideration, especially in the context of an era of heightened scrutiny (Britton, 2008; Connolly et al., 2013; Keating \& Frumkin, 2003; Phillips, 2013). These considerations might also influence the willingness of charities to voluntarily disclose serious incidents in the first place, hampering the ability of the regulator to identify and mitigate risk in the sector. Finally, it is prudent to consider what policy response is appropriate from OSCR, beyond those captured in the data (i.e. further reporting, potential demise). At a time when it is required to do "more with less", is OSCR justified in demanding additional information from charities, and does it possess the resources necessary to offer support, regulatory relief or leniency to charities that do report (Prakash \& Potoski, 2006)? It is only with longitudinal data that we will be able to assess the link between the reporting of serious incidents, organisational outcomes, and the appropriateness of OSCR's response.

There are a number of limitations to this research that must be acknowledged. The first concerns the ambiguity of exactly what a reported incident represents. It could mean that a charity is particularly risky, prone to the sort of incident that would require notifying the regulator. Alternatively, it may mean that the charity has good risk management procedures in place, promptly identifying serious incidents and communicating them to trustees and to the regulator. Another example of this ambiguity is OSCR's list of example serious incidents that have not been reported by the charities in our data (e.g. significant sums of money, other property donated to the charity from an unknown or unverified source): is this evidence of these incidents not occurring, or are they less likely to be reported relative to others? This is a perennial issue for both regulators and researchers. There is a dearth of governance variables in the data and we were not able to examine the influence of these factors as we would have liked. As this is a nascent accountability mechanism for which we have only one year of data, the multivariate results are best considered as indicators of the factors associated with reporting serious incidents. There are also limits to the extent that we can explain behaviour 
using administrative (i.e. secondary) data; for example, we do not capture the degree of investment and intensity that charities commit to engaging in accountability behaviour. As stated previously, it would be remiss to consider the first wave of reporting charities as representative of all charities willing to discharge accountability in this way. Finally, we do not include variables derived from resource dependence theory (e.g. reliance on private donations or government funding); though measures could be constructed using existing data, these would only apply to a subset of larger charities (i.e. annual gross income of at least $£ 250,000)$.

\section{Conclusion}

There are a number of fruitful avenues of research arising from the findings of this study. It would be instructive to understand the factors charities take into account when deciding whether to report serious incidents to the regulator: are they motivated by a sense of moral duty, under pressure from internal or external stakeholders, or, as suggested by Busuioc and Lodge (2016), are they driven by reputational concerns? An in-depth examination of reporting charities could also provide evidence of organisational interest, intensity and investment in accountability relationships, and whether these charities are under more pressure to be transparent in general or just in the context of the Notifiable Events scheme. As longitudinal data becomes available, and participation by charities increases, researchers can focus on the organisational outcomes (for charities and regulators) of engagement with the Notifiable Events reporting scheme. As the sample size grows, further work could also consider finer grained modelling of the different types of serious incidents. Finally, the existence of other serious incident reporting mechanisms in other areas (e.g. England \& Wales) provides the potential for cross-national and/or sectoral comparisons. 
One thing is clear: the increasing availability of high-quality administrative data about the charity sector provides a real opportunity for both researchers and regulators to respond to the call for greater accountability of charitable organisations with a deeper understanding of both the size and distribution of risk in the sector.

\section{Acknowledgments}

The authors would like to thank the Office of the Scottish Charity Regulator (OSCR) for their generous support of the research, especially for granting access to the data. In particular, credit is due to Louise Meikleham, Ann Smith and Judith Turbyne at OSCR for their substantial cooperation and feedback, and the anonymous reviewers for their insightful and constructive comments. 


\section{References}

Allison, P. D. (1999). Multiple Regression: A Primer. London: Sage Publications, Inc.

Behn, B. K., DeVries, D., \& Lin, J. (2007). Voluntary disclosure in nonprofit organizations: An exploratory study. Retrieved March 15, 2018, from http://ssrn.com/abstract=727363.

Bovens, M. (2007). Analysing and Assessing Accountability: A Conceptual Framework. European Law Journal, 13(4), 447-468.

Britton, R. (2008). Making disclosure regulation work in the nonprofit sector. University of Illinois Law Review, 2008(1), 437-458.

Brody, E. (2002). Accountability and public trust. In L. M. Salamon (Ed.), The state of nonprofit America (pp. 471-498). Washington, DC: Brookings Institute.

Brook, O. \& Rutherford, A.C. (2017). Using Administrative Data to Understand Civil Society Organisations in Scotland. ThinkData Working Paper.

Burger, R., \& Owens, T. (2010). Promoting Transparency in the NGO Sector: Examining the Availability and Reliability of Self-Reported Data. World Development, 38(9), 12631277.

Busuioc, M., \& Lodge, M. (2016). Reputation and Accountability Relationships: Managing Accountability Expectations through Reputation. Public Administration Review, Online First, 1-10.

Charity Commission for England and Wales. (2017). Charity Commission Annual Report and Accounts 2016-17. London: Author. 
Coetzee, C. M., \& van Staden, C. J. (2011). Disclosure responses to mining accidents: South African evidence. Accounting Forum, 35(4), 232-246.

Coglianese, C. (2009). The Transparency President? The Obama Administration and Open Government. Governance, 22(4), 529-544 .

Connolly, C., \& Dhanani, A. (2006). Accounting narratives: The reporting practices of British charities. Journal for Public and Nonprofit Services, 35, 39-62.

Connolly, C., \& Hyndman, N. (2000). Charity accounting: An empirical analysis of the impact of recent changes. British Accounting Review, 32(1), 77-100.

Connolly, C., \& Hyndman, N. (2001). A comparative study on the impact of revised SORP 2 on British and Irish charities. Financial Accountability and Management, 17(1), 7397.

Connolly, C., \& Hyndman, N. (2004). Performance reporting: A comparative study of British and Irish charities. British Accounting Review, 36(2), 127-154.

Connolly, C., \& Hyndman, N. (2013a). Charity accountability in the UK: through the eyes of the donor. Qualitative Research in Accounting \& Management, 10(3/4), 259-278.

Connolly, C., \& Hyndman, N. (2013b). Towards Charity Accountability: Narrowing the gap between provision and needs? Public Management Review, 15(7), 945-968.

Connolly, C., Hyndman, N., \& McConville, D. (2013). Conversion Ratios, Efficiency and Obfuscation: A Study of the Impact of Changed UK Charity Accounting Requirements on External Stakeholders. Voluntas: International Journal of Voluntary and Nonprofit Organizations, 24(3), 785-804. 
Connolly, R., Gayle, V., \& Lambert, P. S. (2016). Statistical modelling of key variables in social survey data analysis. Methodological Innovations, 9, 1-17.

Cordery, C. J., \& Morgan, G. G. (2013). Special Issue on Charity Accounting, Reporting and Regulation. Voluntas: International Journal of Voluntary and Nonprofit Organizations, 24(3), 757-759.

Dhanani, A. (2009). Accountability of UK charities. Public Money and Management, 29(3), 183-190.

Ebrahim, A. (2005). Accountability Myopia: Losing Sight of Organizational Learning. Nonprofit and Voluntary Sector Quarterly, 34(1), 56-87.

Frumkin, P. (2006). Strategic Giving: The Art and Science of Philanthropy. Chicago: University of Chicago Press.

Goodin, R. E. (2003). Democratic Accountability: The Distinctiveness of the Third Sector. European Journal of Sociology, 44(3), 359-396.

Gray, R., Brennan, A., \& Malpas, J. (2014). New accounts: Towards a reframing of social accounting. Accounting Forum, 38(4), 258-273.

Hyndman, N. (1990). Charity accounting: An empirical study of the information needs of contributors to UK fundraising charities. Financial Accountability \& Management, 6(4), 295-307.

Hyndman, N. (1991). Contributors to Charities: A Comparison of Their Information Needs and The Perceptions of Such by The Providers of Information. Financial Accountability \& Management, 7(2), 69-82. 
Hyndman, N., \& McConville, D. (2015). Transparency in Reporting on Charities' Efficiency A Framework for Analysis. Nonprofit and Voluntary Sector Quarterly, Online First, $1-22$.

Islam, M. A., Dissanayake, T., Dellaportas, S., \& Haque, S. (2018). Anti-bribery disclosures: A response to networked governance. Accounting Forum, 42(1), 3-16.

Keating, E. K., \& Frumkin, P. (2003). Reengineering Nonprofit Financial Accountability: Toward a More Reliable Foundation for Regulation. Public Administration Review, 63(1), 3-15.

Lehman, G., \& Kuruppu, S. C. (2017). A framework for social and environmental accounting research. Accounting Forum, 41(3), 139-146.

Lehman, G., \& Morton, E. (2017). Accountability, corruption and social and environment accounting: Micro-political processes of change. Accounting Forum, 41(4), 281-288.

Luoma, P., \& Goodstein, J. (1999). Stakeholders and corporate boards: Institutional influences on board composition and structure. Academy of Management Journal, 42(5), 553-563.

McDonnell, D. (2017). Improving Charity Accountability: Lessons From the Scottish Experience. Nonprofit and Voluntary Sector Quarterly, 46(4), 725-746.

McDonnell, D., \& Rutherford, A. C. (2018). The Determinants of Charity Misconduct. Nonprofit and Voluntary Sector Quarterly, 47(1), 107-125.

Morgan, G. G. (2012). Public benefit and charitable status: assessing a 20-year process of reforming the primary legal framework for voluntary activity in the UK. Voluntary Sector Review, 3(1), 67-91. 
Morgan, G. G., \& Fletcher, N. J. (2013). Mandatory Public Benefit Reporting as a Basis for Charity Accountability: Findings from England and Wales. Voluntas: International Journal of Voluntary and Nonprofit Organizations, 24(3), 805-830.

Nie, L., Liu, H. K., \& Cheng, W. (2016). Exploring Factors that Influence Voluntary Disclosure by Chinese Foundations. Voluntas: International Journal of Voluntary and Nonprofit Organizations, 27(5), 2374-2400.

Office of the Scottish Charity Regulator. (2016a). Charities, Public Trust and Regulation 2016 (Research Report). Dundee: Author.

Office of the Scottish Charity Regulator. (2016b). Reporting Notifiable Events to the Scottish Charity Regulator. Dundee: Author.

Ortmann, A., \& Schlesinger, M. (1997). Trust, repute and the role of non-profit enterprise. Voluntas: International Journal of Voluntary and Nonprofit Organizations, 8(2), 97119.

Parsa, S., Roper, I., Muller-Camen, M., \& Szigetvari, E. (2018). Anti-bribery disclosures: A response to networked governance. Accounting Forum, 42(1), 47-64.

Phillips, S. D. (2013). Shining Light on Charities or Looking in the Wrong Place? Regulation-by-Transparency in Canada. Voluntas: International Journal of Voluntary and Nonprofit Organizations, 24(3), 881-905.

PKF Littlejohn. (2016). Annual Fraud Indicator 2016 (Research Report). London: Author.

Prakash, A., \& Gugerty, M. K. (2010). Trust but verify? Voluntary regulation programs in the nonprofit sector. Regulation \& Governance, 4(1), 22-47. 
Prakash, A., \& Potoski, M. (2006). Racing to the Bottom? Trade, Environmental Governance, and ISO 14001. American Journal of Political Science, 50(2). 350-364.

Saxton, G. D., \& Guo, C. (2011). Accountability Online: Understanding the Web-Based Accountability Practices of Nonprofit Organizations. Nonprofit and Voluntary Sector Quarterly, 40(2), 270-295.

Saxton, G. D., Kuo, J., \& Ho, Y. (2012). The Determinants of Voluntary Financial Disclosure by Nonprofit Organizations. Nonprofit and Voluntary Sector Quarterly, 41(6), 10511071.

Scottish Council for Voluntary Organisations (2014). State of the Sector (Research Report). Edinburgh: Author.

Tacon, R., Walters, G., \& Cornforth, C. (2017). Accountability in non-profit governance: A process-based study. Nonprofit and Voluntary Sector Quarterly, 46(4), 685-704.

Tremblay-Boire, J., \& Prakash, A. (2015). Accountability.org: Online Disclosures by U.S. Nonprofits. Voluntas: International Journal of Voluntary and Nonprofit Organizations, 26(2), 693-719.

Tremblay-Boire, J., \& Prakash, A. (2017). Will You Trust Me?: How Individual American Donors Respond to Informational Signals Regarding Local and Global Humanitarian Charities. Voluntas: International Journal of Voluntary and Nonprofit Organizations, 28(2), 621-647.

Tremblay-Boire, J., Prakash, A., \& Gugerty, M. K. (2016). Regulation by Reputation: Monitoring and Sanctioning in Nonprofit Accountability Clubs. Public Administration Review, 76(5), 712-722. 
Yasmin, S., Haniffa, R., \& Hudaib, M. (2014). Communicated Accountability by Faith-Based Charity Organisations. Journal of Business Ethics, 122(1), 103-123. 


\section{Tables and Figures}

Table 1. Charity Accountability Dataset: Sample Selection Process

Sample Selection

Initial sample in Scottish Charity Register

47,285

Removal of charities with invalid legal names

(corresponds to organizations never recognised

by previous regulatory regime)

Removal of charities never recognised by

OSCR when it took up its regulatory powers or those subsequently removed during the process of establishing an accurate charity register

Removal of charities with income of $£ 0$

Removal of charities with missing data for income

Removal of charities that are inactive, nonsubmitting or not monitored

Final sample

20,400 charities

Note: Non-submitting charities were removed on the advice of OSCR; they are registered charities but have failed to comply with their reporting requirements. Though encouraged to report to their main regulator instead of OSCR, we included notifiable events reported by Cross Border charities $(n=8)$ and Registered Social Landlords $(n=1)$. 
Table 2. Conceptual Framework

\begin{tabular}{|c|c|c|}
\hline Factor & Variable & Operationalisation \\
\hline \multirow[t]{3}{*}{ Strategy } & Funder & $\begin{array}{l}1=\text { Disburses grants to other organisations } \\
0=\text { Carries out charitable activities itself or a } \\
\text { combination of functions }\end{array}$ \\
\hline & Unincorp & $\begin{array}{l}1=\text { Charity is registered as an unincorporated } \\
\text { association }\end{array}$ \\
\hline & & $\begin{array}{l}0=\text { Charity is not registered as an } \\
\text { unincorporated association (e.g. company, } \\
\text { trust) }\end{array}$ \\
\hline \multirow[t]{4}{*}{ Capacity } & Size & $1=£ 1-£ 99,999$ \\
\hline & & $2=£ 100,000-£ 499,999$ \\
\hline & & $3=£ 500,000+$ \\
\hline & Age & $\begin{array}{l}\text { Natural log of the number of years a charity } \\
\text { has existed (most recent annual return year - } \\
\text { registration year) }\end{array}$ \\
\hline Governance & Parent & $\begin{array}{l}1=\text { Charity has a parent organisation } \\
0=\text { Charity does not have a parent } \\
\text { organisation }\end{array}$ \\
\hline \multirow[t]{4}{*}{ Environment } & Investigated & $\begin{array}{l}1=\text { OSCR has opened an inquiry case into a } \\
\text { complaint against a charity in the previous } \\
\text { two years }\end{array}$ \\
\hline & & $\begin{array}{l}0=\text { OSCR has not opened an inquiry case into } \\
\text { a complaint against a charity in the previous } \\
\text { two years }\end{array}$ \\
\hline & Local & $\begin{array}{l}1=\text { Conducts its operations at a local level } \\
\text { only }\end{array}$ \\
\hline & & $\begin{array}{l}0=\text { Conducts its operations at a wider } \\
\text { geography (e.g. overseas) }\end{array}$ \\
\hline
\end{tabular}


Table 3. Descriptive Statistics for the Outcome of Reporting

\begin{tabular}{|c|c|c|c|c|c|c|c|}
\hline \multirow[b]{2}{*}{ Variable } & & \multicolumn{2}{|c|}{$\begin{array}{c}\text { Do not report } \\
(n=20,306)\end{array}$} & \multicolumn{2}{|c|}{$\begin{array}{c}\text { Report } \\
(n=94)\end{array}$} & \multicolumn{2}{|c|}{$\begin{array}{l}\text { Whole sample } \\
(n=20,400)\end{array}$} \\
\hline & & $\mathrm{M}$ & SD & $\mathrm{M}$ & $\mathrm{SD}$ & $\mathrm{M}$ & SD \\
\hline Age (log) & & 2.77 & 1.01 & 3.07 & 1.03 & 2.77 & 1.01 \\
\hline Grant & & .32 & .47 & .23 & .43 & .32 & .47 \\
\hline Parent & & .15 & .36 & .14 & .35 & .15 & .36 \\
\hline Local & & .43 & .49 & .21 & .41 & .43 & .49 \\
\hline Unincorp & & .16 & .36 & .09 & .28 & .16 & .36 \\
\hline Investigated & & .03 & .17 & .16 & .37 & .03 & .17 \\
\hline \multirow[t]{3}{*}{ Size $(\%)$} & $£ 1-£ 99,999$ & 53 & - & 9 & - & 53 & - \\
\hline & $£ 100,000-£ 499,999$ & 37 & & 49 & & 37 & \\
\hline & $£ 500,000+$ & 10 & & 43 & & 10 & \\
\hline
\end{tabular}

Note: Figures rounded to two decimal places or nearest whole number for percentages. 
Table 4. Results of Logistic Regression for Outcome of Reporting

\begin{tabular}{|c|c|c|c|c|c|}
\hline & & \multirow[t]{2}{*}{ Log odds } & \multirow[t]{2}{*}{ SE (robust) } & \multicolumn{2}{|c|}{$95 \% \mathrm{CI}$} \\
\hline & & & & Lower & Upper \\
\hline \multirow[t]{3}{*}{ Size } & $£ 1-£ 99,999$ & Ref. & - & - & - \\
\hline & $£ 100,000-£ 499,999$ & $1.90 * * *$ & .40 & 1.12 & 2.68 \\
\hline & $£ 500,000+$ & $2.94 * * *$ & .42 & 2.11 & 3.77 \\
\hline Age & & $.35 * *$ & .13 & .10 & .60 \\
\hline Funder & & -.46 & .25 & -.96 & .03 \\
\hline Unincorp & & -.34 & .40 & -1.12 & .45 \\
\hline Parent & & -.26 & .37 & -.98 & .46 \\
\hline Local & & -.46 & .30 & -1.05 & .13 \\
\hline Investigated & & $.95 * *$ & .31 & .35 & 1.55 \\
\hline$n$ & \multicolumn{5}{|c|}{20,400} \\
\hline $\begin{array}{l}\text { McFadden's } \\
\text { adjusted } \mathrm{R}^{2}\end{array}$ & \multicolumn{5}{|c|}{.09} \\
\hline $\begin{array}{l}\text { McKelvey and } \\
\text { Zavoina's R }{ }^{2}\end{array}$ & \multicolumn{5}{|c|}{.34} \\
\hline $\begin{array}{l}\text { Cragg and Uhler's } \\
\mathrm{R}^{2}\end{array}$ & \multicolumn{5}{|c|}{.12} \\
\hline BIC full model & \multicolumn{5}{|c|}{$-201,227.75$} \\
\hline
\end{tabular}

Note: Figures rounded to two decimal places. Constant is omitted. CI: confidence interval;

BIC: Information Criterion. $* \mathrm{p}<.05 . * * \mathrm{p}<.01 . * * * \mathrm{p}<.001$. 
Table 5. Mapping Serious Incidents

\begin{tabular}{lccc}
\hline & & \multicolumn{2}{c}{ Serious Incident } \\
& & Yes & No \\
\cline { 3 - 4 } Motivation to Report & Yes & Report & In Future \\
& No & Unreported & Never \\
\hline
\end{tabular}


Figure 1. Reported Serious Incidents and Regulator Response

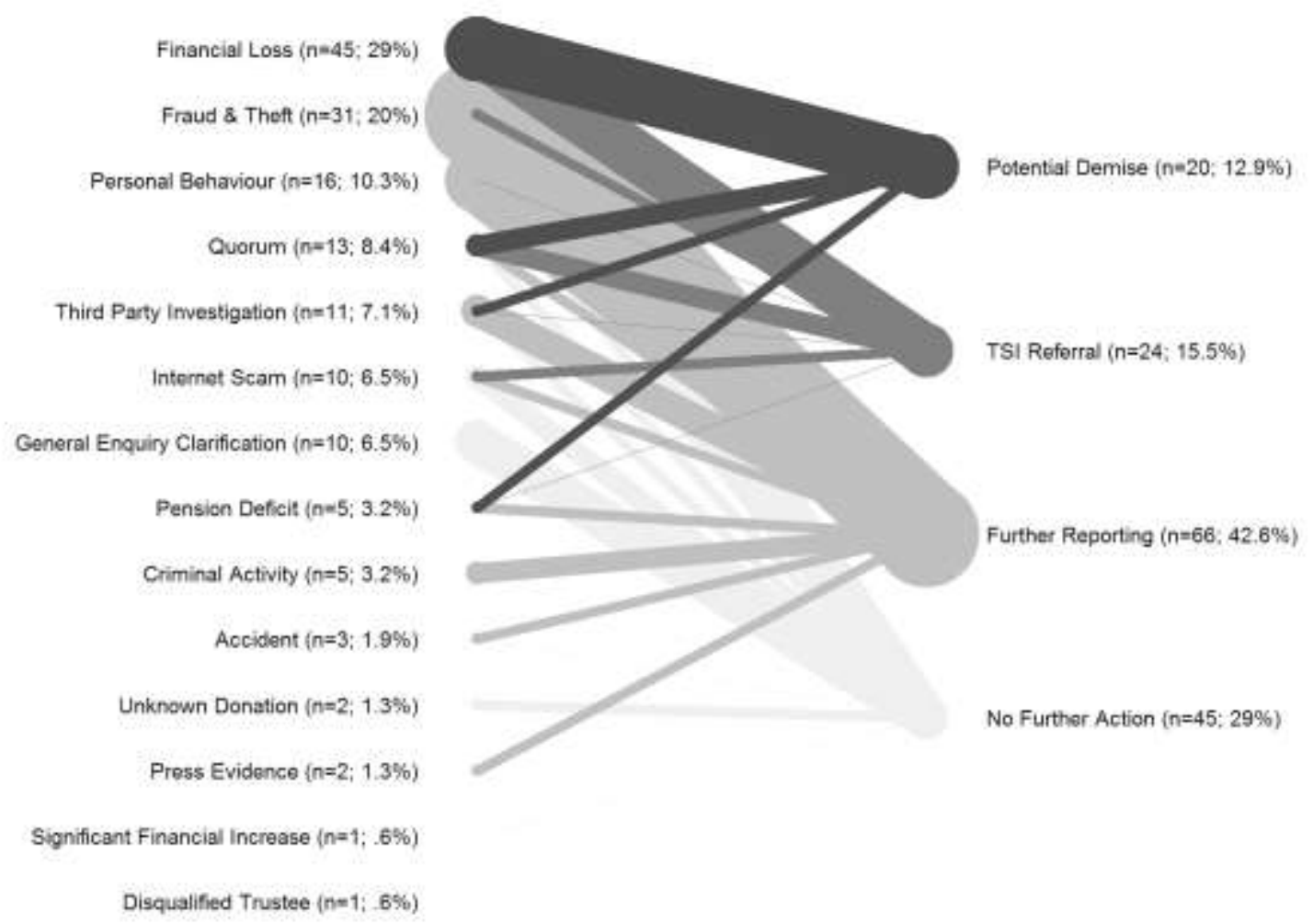

Note: Serious incident types are shown in the left of the diagram, and regulator response on the right. The thickness of the line represents the strength of the association between an incident and a response: for instance, Fraud \& Theft incidents very often require further reporting by the charity to OSCR. A serious incident can be marked with more than one response, so the percentages on the right do not sum to 100 percent. Association between serious incident and regulator response: potential demise (Cramer's $\mathrm{V}=0.67, \mathrm{p}<.001$ ); further reporting (Cramer's V =0.61, $\mathrm{p}<.001$ ); and TSI referral (Cramer's V $=0.54, \mathrm{p}<$ $.001)$. 
[IN COLOUR] Figure 2. Distribution of Serious Incidents, by Charity Age and Size

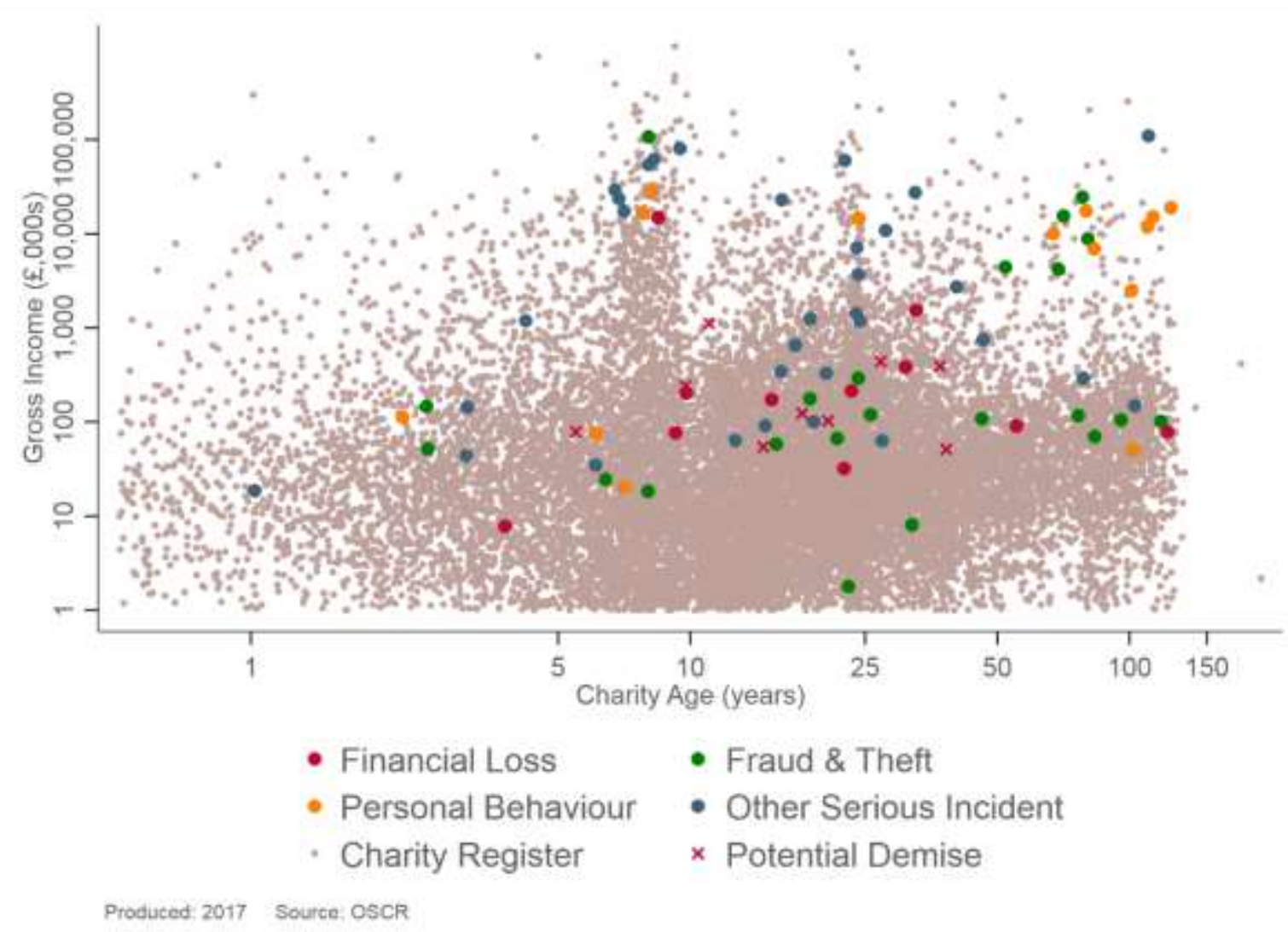

Note: Each large point represents an organisation reporting a serious incident. The incident type is indicated by the label. Red crosses indicate OSCR's concern that there is a risk of organisational demise arising from the incident. 
Figure 3. Estimated Reporting Rate of Serious Incidents, by Charity Age and Size
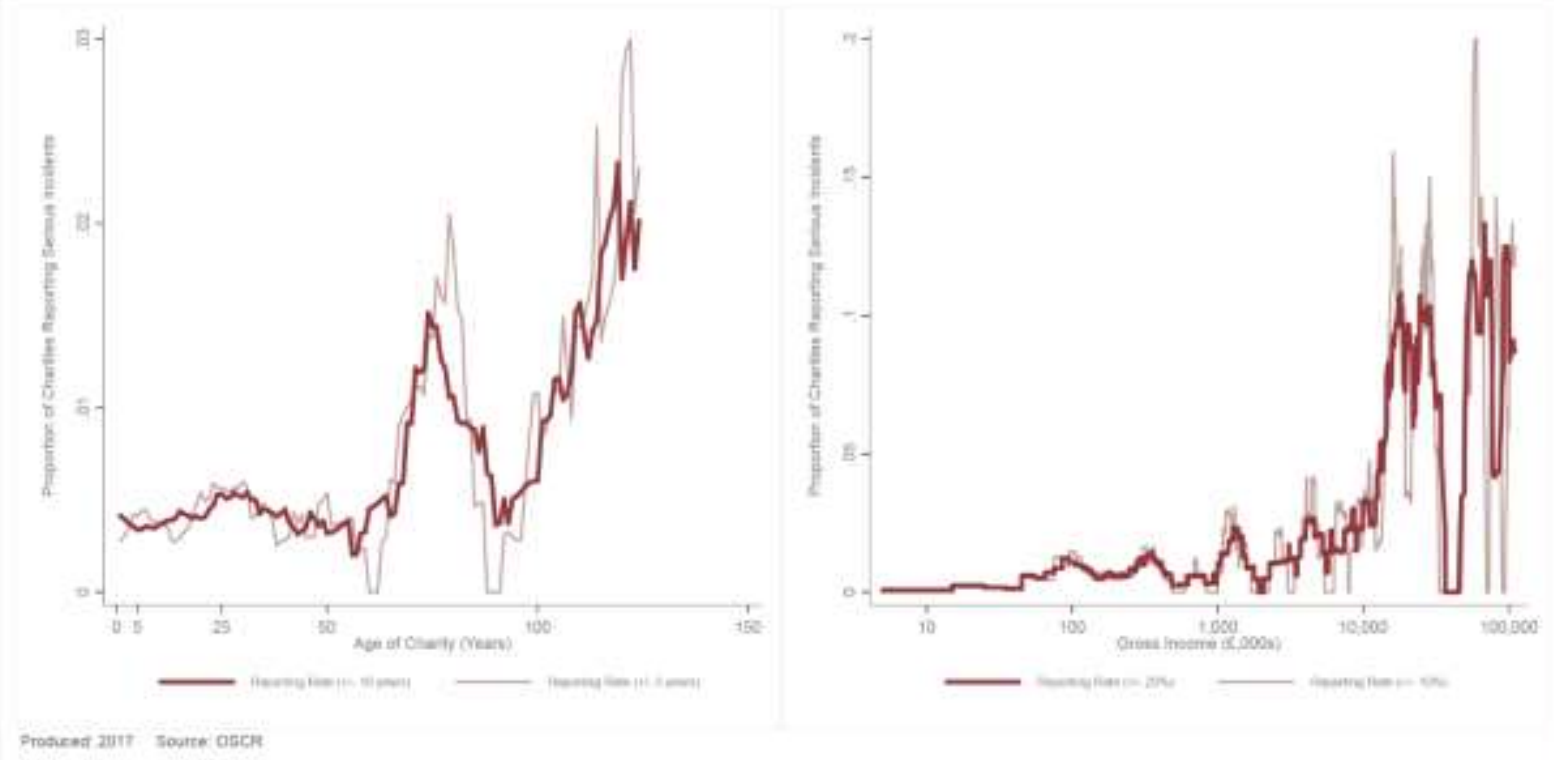

Note: Reported incidents are relatively rare in the sample, and so calculations of the reporting rate are sensitive to the choice of grouping within metric variables. In order to account for this, the reporting rate is calculated as a moving average across charity age (gross income). The dark red line calculates the proportion of charities reporting an incident for organisations $+/-10$ years (+/- $20 \%$ gross income), while the light red line shows the proportion for organisations $+/-5$ years $(+/-10 \%$ gross income). The graph shows that the reporting rate increases in both age and income, and most steeply at the top of the age and income distributions. However, there is a cluster of higher reporting for charities aged around 70 to 80 years old. Similarly, there is a cluster of higher than average reporting rates for charities around the $£ 12$ million income level. 
[IN COLOUR] Figure 4. Distribution of Risk in the Scottish Charity Sector, by Charity Age and Size

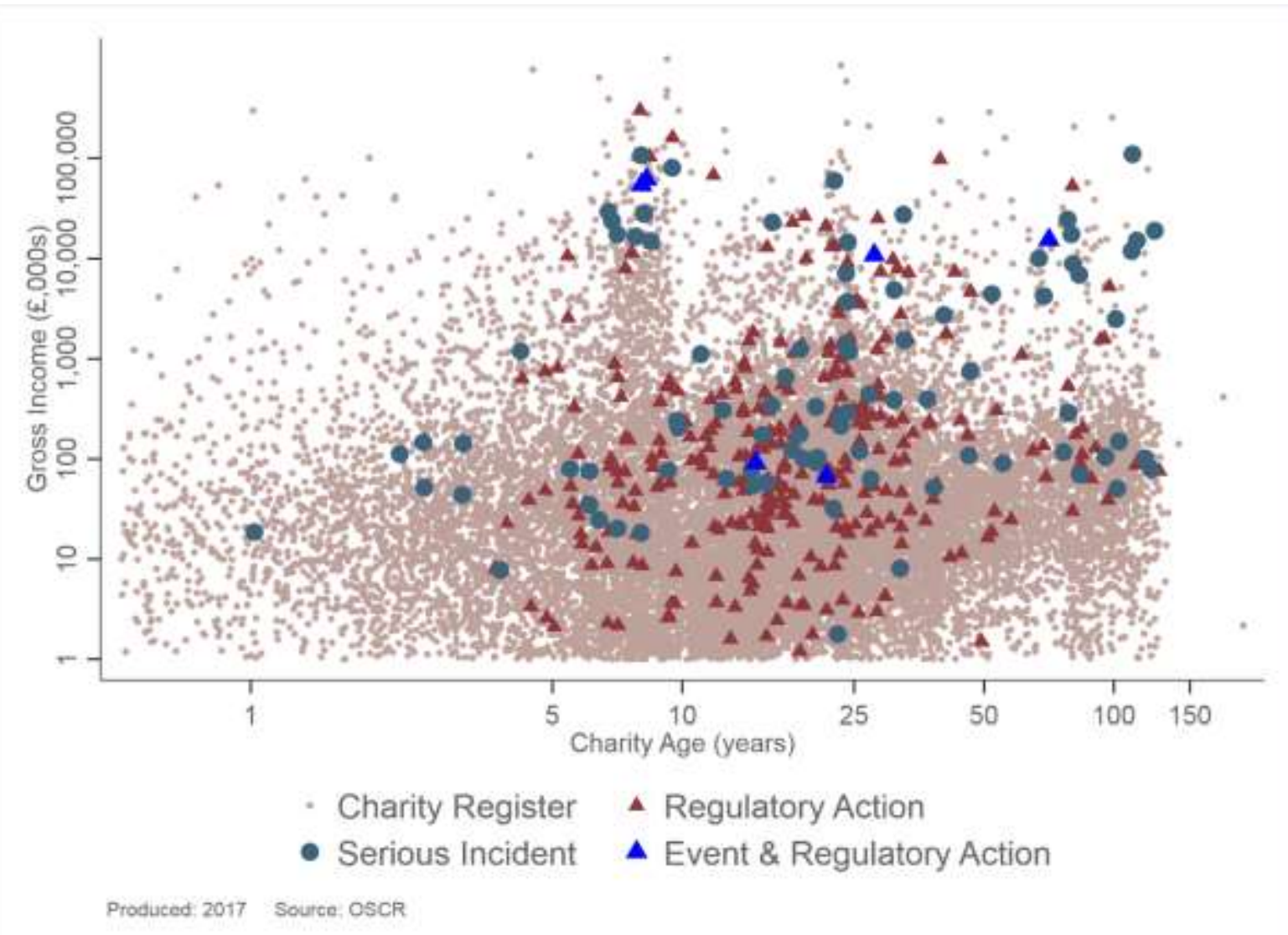

